\title{
Maternal Dietary Supplementation with Pomegranate Juice Is Neuroprotective in an Animal Model of Neonatal Hypoxic-Ischemic Brain Injury
}

\author{
DAVID J. LOREN, NAVINDRA P. SEERAM, RISA N. SCHULMAN, AND DAVID M. HOLTZMAN \\ Division of Neonatology, University of Washington, Seattle, WA 98195 [D.J.L.]; Departments of \\ Pediatrics [D.J.L.], Neurology [D.M.H.], and Molecular Biology and Pharmacology [D.M.H.], Center for \\ the Study of Nervous System Injury [D.M.H.], Washington University School of Medicine, St. Louis, \\ Missouri 63110; Center for Human Nutrition [N.P.S.], David Geffen School of Medicine, University of \\ California School of Medicine [R.N.S.], Los Angeles, California 90095
}

\begin{abstract}
ABST
Neonatal hypoxic-ischemic brain injury remains a significant
cause of morbidity and mortality and lacks effective therapies for
prevention and treatment. Recently, interest in the biology of
polyphenol compounds has led to the discovery that dietary
supplementation with foods rich in polyphenols ( $e$.g. blueberries,
green tea extract) provides neuroprotection in adult animal mod-
els of ischemia and Alzheimer's disease. We sought to determine
whether protection of the neonatal brain against a hypoxic-
ischemic insult could be attained through supplementation of the
maternal diet with pomegranate juice, notable for its high poly-
phenol content. Mouse dams were provided ad libitum access to
drinking water with pomegranate juice, at one of three doses, as
well as plain water, sugar water, and vitamin C water controls
during the last third of pregnancy and throughout the duration of
litter suckling. At postnatal day 7 , pups underwent unilateral
carotid ligation followed by exposure to $8 \%$ oxygen for 45 min.
Brain injury was assessed histologically after 1 wk (percentage
\end{abstract}
Neonatal hypoxic-ischemic brain injury is a significant cause of mortality and permanent disability in the perinatal period with an incidence estimated at 2 per 1000 live births $(1,2)$. It can lead to encephalopathy, seizures, and permanent motor impairment, including cerebral palsy $(3,4)$. Accurately predicting which fetuses are at risk for brain injury from $\mathrm{HI}$ is extremely challenging, and interventions that have been tested to date have been directed at rescue modalities. Strategies that

Received July 7, 2004; accepted October 13, 2004.

Correspondence: David M. Holtzman, M.D., Department of Neurology, Washington University, 660 S. Euclid Avenue, Box 8111, St. Louis, MO 63110; e-mail: holtzman@neuro.wustl.edu.

Supported in part by funds from the Stewart and Lynda Resnick Revocable Trust and the National Institutes of Health (NS35902).

DOI: 10.1203/01.PDR.0000157722.07810.15 of tissue area loss) and biochemically after $24 \mathrm{~h}$ (caspase-3 activity). Dietary supplementation with pomegranate juice resulted in markedly decreased brain tissue loss $(>60 \%)$ in all three brain regions assessed, with the highest pomegranate juice dose having greatest significance $(p \leq 0.0001)$. Pomegranate juice also diminished caspase- 3 activation by $84 \%$ in the hippocampus and $64 \%$ in the cortex. Ellagic acid, a polyphenolic component in pomegranate juice, was detected in plasma from treated but not control pups. These results demonstrate that maternal dietary supplementation with pomegranate juice is neuroprotective for the neonatal brain. (Pediatr Res 57: 858-864, 2005)
Abbreviations
DEVD-AMC, Asp-Glu-Val-Asp-7-amino-4-methyl coumarin
HI, hypoxia-ischemia
LCMS, liquid chromatography mass spectrometry

are neuroprotective in animal models include agents and therapies that antagonize the excitotoxic cascade, inhibit apoptosis activation, reduce nitric oxide synthesis, and decrease free radical generation (5-11). After neonatal $\mathrm{HI}$, there is a rapid necrotic injury as well as a delayed apoptotic injury $(10,12,13)$. Despite the prolonged apoptotic injury, a significant issue remains that even if a strong neuroprotectant is identified, by the time a neonate who is experiencing hypoxic-ischemic insult is recognized, it may be too late for the agent to have an effect. Another approach would be to administer a protective agent to all mothers during pregnancy so that if a hypoxic-ischemic insult occurred, the agent would already be present at therapeutic levels. A similar population-based preventive approach-enriching the maternal diet with folic acid-has decreased the incidence of neural tube defects by up to $70 \%$ (14). 
The ideal neuroprotective candidate agent would be systemically deliverable, would possess a wide therapeutic window, would be easily stored, and could be provided throughout the peripartum period to the expecting mother in a safe manner. In this study, we adopted the paradigm of pretreatment in an attempt to provide neonatal neuroprotection through manipulation of the maternal diet. Dietary supplementation with foods rich in polyphenols - blueberries, green tea, and apple juicehas been shown to provide neuroprotection in an animal model of focal brain ischemia, an animal model of periventricular white matter injury, and an animal model of Alzheimer's disease (15-19).

Polyphenols-molecules that are defined by the presence of an aromatic ring bearing one or more hydroxyl substitutes-are products of plant metabolism (20). These compounds have been found to possess antioxidant properties as well as to have effects on gene expression (21). Specifically, one polyphenol, resveratrol, a recognized constituent of red and white grapes and a variety of plants and trees, has been shown to increase activity of members of the sirtuin gene class, blunting p53 action and blocking apoptosis (22-24). Recent studies indicate that among foods that contain polyphenols, juice extracted from the pomegranate has the highest concentration of measurable polyphenols $(25,26)$ (Aviram M, unpublished data, 2002). The pharmacologic actions of pomegranate juice include antiatherosclerotic, antibacterial, and antiproliferative properties $(27,28)$. Studies of dietary supplementation with pomegranate juice have shown protective effects against atherogenesis and atherosclerosis as well as reduction in serum angiotensin-converting enzyme activity with subsequent reduction in systolic blood pressure (29-31). Given these results, we wondered whether maternal dietary supplementation with pomegranate juice would result in protection against neonatal brain injury. We used a well-characterized model of term neonatal $\mathrm{HI}$ to investigate the neuroprotective capability of pomegranate juice in a pretreatment paradigm (32). Results show that there was a strong neuroprotective effect of pomegranate juice, suggesting that such an approach should be explored further as a potential prevention strategy.

\section{METHODS}

Animal protocol. The Washington University animal studies committee approved this protocol. Mature C57BL6 mice (all reproductively naïve at approximately similar birth ages) were obtained from Taconic (Germantown, NY) and were housed in a light cycle-controlled approved animal facility. Breeding pairs were established, and mice were provided ad libitum access to rodent diet and water. Once pregnancy was identified (breeding cages were inspected daily, pregnancy is most commonly recognized at $\sim$ E14 with delivery ensuing typically at $\sim \mathrm{E} 21$ ), the pregnant mouse was placed in a solitary cage and provided ad libitum access to plain water or water modified with supplements as described below. Neonatal HI was performed as previously described (33-35). Briefly, at postnatal day 7 (P7), pups were anesthetized with halothane (induction at 5\%, maintenance at $1 \%$, balance of gas as room air) and the left common carotid artery was exposed and Bovie cauterized (Aaron Medical, St. Petersburg, FL). Skin was re-approximated with Nexaband (Abbott Laboratories, North Chicago, IL). Total anesthesia time per animal was typically $3 \mathrm{~min}$. Pups recovered in a humidified room air incubator for $\sim 30 \mathrm{~min}$ and then returned to the cage with the dam for $\sim 1.5 \mathrm{~h}$. Exposure to hypoxia then was performed in sealed $500-\mathrm{mL}$ chambers immersed in a $37^{\circ} \mathrm{C}$ water bath that was supplied with humidified $8 \%$ oxygen, with balance $92 \%$ nitrogen, for $45 \mathrm{~min}$. Pups then recovered again in a humidified room air incubator for
30 min and were returned to the dam. Pups were weighed during the first day after birth and at P7 just before exposure to HI.

Treatment. Pregnant mice were provided drinking fluid that contained either a high dose of pomegranate juice concentrate (Wonderful variety of pomegranates, POM Wonderful, Los Angeles, CA) diluted 1:80 in deionized, filtered water estimated to provide $32 \mu \mathrm{mol}$ of polyphenols per day, a middle dose of pomegranate juice (1:160 dilution of pomegranate juice concentrate estimated to provide $16 \mu \mathrm{mol}$ of polyphenols per day), or a low dose of pomegranate juice (1:320 dilution of pomegranate juice concentrate estimated to provide $8 \mu \mathrm{mol}$ of polyphenols per day). Sugar water control was prepared to replicate the sugar mixture and content of the middle dose dilution of pomegranate juice concentrate. Specifically, $240 \mathrm{~mL}$ of pomegranate juice at middle-dose dilution contains $35 \mathrm{~g}$ of sugars. Sugar water was made to contain $\sim 85 \%$ sucrose (Fisher Scientific, Fair Lawn, NJ) and 15\% D-(+)-glucose (Sigma Chemical Co., St. Louis, MO) and D-fructose (Fisher Scientific) in equal proportion. Vitamin $\mathrm{C}$ control water was mixed to provide the equivalent dose of $15 \%$ of the U.S. recommended dietary allowance $(45 \mathrm{mg} / \mathrm{d}$ for female humans) of vitamin $\mathrm{C}$ intake based on an average adult mouse fluid consumption of $5 \mathrm{~mL} / \mathrm{d}$. Specifically, $0.45 \mathrm{mg}$ of L-ascorbic acid (Fisher Scientific) was diluted in $100 \mathrm{~mL}$ of deionized water. All drinking fluids except plain water were provided in red light-blocking bottles (Ancare, Bellmore, NY). Total treatment time for all groups was typically $15 \mathrm{~d}(7 \mathrm{~d}$ in utero and $8 \mathrm{~d}$ ex utero) for mice that underwent caspase- 3 analysis and $21 \mathrm{~d}(7 \mathrm{~d}$ in utero and $14 \mathrm{~d} e x$ utero) for mice that underwent histologic analysis. There was no more than $1 \mathrm{~d}$ of variation in the in utero treatment time between litters. Maternal age did not significantly differ between the groups. All treatment group dams consumed on average $2 \mathrm{~mL}$ of fluid per day with no observed differences between any group. All treatment groups were provided ad libitum access to rodent diet; caloric consumption was approximated by quantification of maternal weight change. No differences were noted in weight between mothers of different treatment groups. All pups, male and female, were used in these experiments.

Histologic measurements. Mouse pups at P14 (7 d after HI) were anesthetized with $200 \mathrm{mg} / \mathrm{kg}$ i.p. pentobarbital, perfused through the left ventricle with heparinized 0.1 M PBS, and decapitated. We analyzed tissue loss at this time point as it is clear cut and easily quantifiable $(11,33,34,36)$. Furthermore, although the amount of tissue loss continues after P14, it is mostly complete at this time in the mouse (D.M. Holtzman, unpublished observations). The whole brain was removed, fixed in $4 \%$ paraformaldehyde for $24 \mathrm{~h}$ at $4{ }^{\circ} \mathrm{C}$, and transferred to $30 \%$ sucrose (wt/vol) in PBS at $4^{\circ} \mathrm{C}$. Coronal sections $(50 \mu \mathrm{m})$ were cut on a freezing sliding microtome from the genu of the corpus callosum caudally to the end of the hippocampus and were stained with cresyl violet after mounting on Superfrost glass slides. Cross-sectional areas of the striatum, hippocampus, and cortex were measured in each of eight equally spaced samples with SigmaScan Pro 5 (Jandel Corp., San Rafael, CA). The total cross-sectional area for each brain region was calculated, and the percentage of area loss in the injured (ipsilateral) versus noninjured (contralateral) hemispheres was determined for each animal as previously described (10,36). Slides were assigned a random number matched to the respective litter, and the histologic analysis was performed by the investigator (D.L.) who was blinded to treatment group.

Caspase-3 activity assay. Twenty-four hours after hypoxic-ischemic exposure at P7, pups were killed and perfused as described above. Hippocampus and cortex from ipsilateral and contralateral hemispheres were dissected on iced glass and snap-frozen in dry ice. Whole-cell protein extracts for each sample were prepared via homogenization in $400 \mu \mathrm{L}$ of tissue lysis buffer [10 $\mathrm{mM}$ HEPES, $7.5 \mathrm{mM} \mathrm{MgCl} 2$, 2 mM EGTA, $1 \%$ Triton-X, $1 \%$ 2-mercaptoethanol, and protease inhibitor (Roche Molecular Biochemicals, Indianapolis, $\mathrm{IN})$ ], adjusted to $\mathrm{pH} 7.4$ ) and centrifuged at $12,000 \times \mathrm{g}$ for $10 \mathrm{~min}$ at $4^{\circ} \mathrm{C}$. Protein concentration of the lysates was determined with a bicinchoninic acid protein assay kit (Pierce, Rockford, IL). Ten microliters of each sample was incubated in a 96-well plate with $90 \mu \mathrm{L}$ of assay buffer (10 mM HEPES, 42

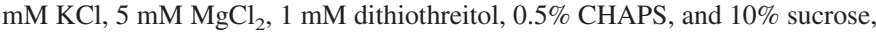
adjusted to $\mathrm{pH}$ 7.4) that contained $30 \mu \mathrm{M}$ Asp-Glu-Val-Asp-7-amino-4-methyl coumarin (DEVD-AMC; Calbiochem, La Jolla, CA). Emitted fluorescence was measured in 5-min intervals for $30 \mathrm{~min}$ at room temperature with an excitation wavelength of $360 \mathrm{~nm}$ and an emission wavelength of $460 \mathrm{~nm}$ using the Bio-Tek (Winooski, VT) FL600 microplate fluorescence reader. DEVD cleavage activity was obtained from the slope of fluorescent units per time. Standard curves were generated from Ac-AMC (Calbiochem) dilutions in assay buffer. Caspase-3 enzyme activity then was expressed as picomoles of AMC per microgram of protein per minute.

Ellagic acid detection. Mouse pups in the high-dose pomegranate juice supplementation group at P14, $7 \mathrm{~d}$ after hypoxic-ischemic exposure, were anesthetized with pentobarbital as described above. Whole blood was withdrawn from the left atrium into $1-\mathrm{mL}$ syringes that first were washed with 0.5 molar EDTA. Plasma was separated from whole blood by centrifuge at 12,000 $\times g$ at $4^{\circ} \mathrm{C}$. Because of the low volumes of mouse plasma collected and the 
levels of instrument sensitivity, plasma samples from the treatment group were pooled (1330 $\mu \mathrm{L}$ final volume), processed, and then analyzed by HPLC (Zorbax SB C-18 column, Agilent Technologies, Palo Alto, CA; Millenium ${ }^{32}$ Chromatography Software, Milford, MA) and liquid chromatography mass spectrometry (LCMS; HP 1100LC; Hewlett-Packard, Palo Alto, CA) methods as previously reported $(37,38)$. Briefly, acetonitrile and phosphoric acid were added to the plasma to precipitate proteins, and the mixture was centrifuged at $3500 \times g$ for $10 \mathrm{~min}$ at $5-10^{\circ} \mathrm{C}$. The supernatant liquor was evaporated to dryness in a SpeedVac, reconstituted to a smaller volume $(100 \mu \mathrm{L})$ in methanol, and then injected $(25 \mu \mathrm{L})$ onto the HPLC. A separate sample $(25$ $\mu \mathrm{L})$ was also injected on the LCMS to confirm the identity of ellagic acid.

Statistics. Continuous variables (percentage area tissue loss, caspase-3 activity, pup weight) are presented as mean \pm SEM. Statistical significance of intergroup differences was determined by one-way ANOVA followed by a post hoc Dunnett's multiple comparison test for analysis of tissue loss and pup weights. A two-tailed $t$ test was used to compare the injured hemispheres in the two groups in the caspase- 3 assay

\section{RESULTS}

To determine whether exposure to substances that are present in pomegranate juice influenced brain injury as a result of neonatal HI, P7 mice from dams that received pomegranate juice supplementation or not in their drinking water underwent unilateral (left) carotid ligation followed by exposure to $45 \mathrm{~min}$ of hypoxia ( $8 \%$ oxygen). One week later, at P14, mice were killed and brains were assessed for extent of tissue loss. In this model, tissue loss occurs in the brain hemisphere ipsilateral but not contralateral to carotid ligation. Pups from litters that were exposed to plain water, sugar water, or vitamin C-supplemented water all had $\sim 40 \%$ loss of hippocampal tissue and $\sim 10-20 \%$ loss of cortical and striatal tissue in the hemisphere ipsilateral to carotid ligation (Fig. 1). The amount of tissue damage did not differ significantly among these three groups, and the amount of damage was virtually identical to what we have previously seen in this model using C57/BL6 mice $(33,34)$. Strikingly, pups in litters that were exposed to low-, middle-, and high-dose pomegranate juice had much less brain injury (Fig. 1). The group that received high-dose pomegranate juice had $>50 \%$ less tissue injury compared with the plain water control group, and the effect in this group was of highest statistical significance $[p<0.0001$; percentage area loss \pm SEM; high-dose pomegranate juice $(n=11)$ : hippocampus, $15.9 \pm 3.5 \%$; cortex, $2.5 \pm 1.2 \%$; striatum, $5.4 \pm 2.4 \%$; plain water control $(n=15)$ : hippocampus, $42.4 \pm 5.2 \%$; cortex, $20.3 \pm 2.8 \%$; striatum, $20.1 \pm 3.1 \%$ ]. Although there was a trend for a dose-dependent effect of pomegranate juice supple- mentation, the amount of injury in all groups that received pomegranate juice did not differ significantly from each other.

To both validate these results and to begin to assess whether pomegranate juice decreased certain types of cell death, we subjected additional litters of mice that were exposed to highdose pomegranate juice or plain water to $\mathrm{HI}$ at $\mathrm{P7}$ and then quantitatively assessed the amount of caspase- 3 activation in brain tissue lysates $24 \mathrm{~h}$ after HI. Caspase-3 activation is a marker of apoptotic death and has previously been shown to be markedly increased after $\mathrm{HI}$ in the neonatal brain $(10,39)$. As seen with brain tissue loss, litters that were exposed to highdose pomegranate juice had significantly less DEVDase activity, a marker of caspase- 3 activation, in both the hippocampus and the cortex compared with controls (Fig. 2). The decrease in caspase-3 activity was somewhat greater in the hippocampus ( $84 \%$ decrease) versus the cortex (64\% decrease).

To validate the presence of pomegranate juice components in the mouse pups, we collected plasma from pups that were exposed to maternal pomegranate juice supplementation as well as all three control groups. Ellagic acid, a polyphenol found in high concentrations in pomegranate juice, was detected in mouse plasma from the treatment group using HPLC-UV as previously reported (38). On the basis of this method, we estimated the plasma ellagic acid concentration at $\sim 1.8 \mathrm{ng} / \mathrm{mL}$. The presence of ellagic acid in mouse plasma from the treatment group was confirmed by LCMS at a molecular ion of $\mathrm{m} / \mathrm{z}\left(\mathrm{M}-\mathrm{H}^{+}\right)$of 301 (Fig. 3A) and by tandem LCMS analyses as previously reported with molecular ions at $\mathrm{m} / \mathrm{z} 257$ and 229 as distinct from quercetin, which would have ions at $\mathrm{m} / \mathrm{z} 179$ and $151(37,40)$ (Fig. 3B). Ellagic acid was not detected in plasma samples that were collected from mice from the control groups. This confirms maternal gastrointestinal absorption of pomegranate juice components and passage of polyphenol compounds across the mouse placenta from maternal serum to pup serum.

To determine whether exposure to pomegranate juice resulted in other differences between the groups, we assessed the weight of pups immediately after birth and just before exposure to HI. Mean birth weights of pups in the various groups were not significantly different (data not shown). At P7, immediately before HI, pups in the plain water group did not differ in weight from those in the high-dose pomegranate juice or vitamin $\mathrm{C}$
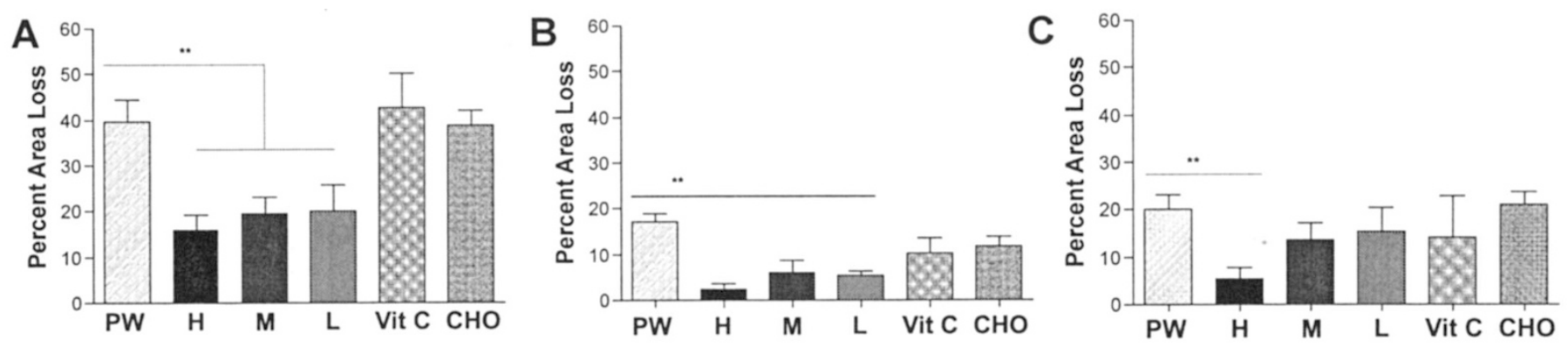

Figure 1. Pomegranate juice $(\mathrm{PJ})$ protects against brain tissue loss following neonatal HI. Percent of tissue loss in injured versus uninjured brain hemispheres at 7 days after HI exposure: $(A)$ hippocampus, $(B)$ cortex, and $(C)$ striatum, respectively, in pups suckling from dams provided plain water $(\mathrm{PW} ; n=11)$; high $(\mathrm{H} ; n=11)$, mid $(\mathrm{M} ; n=11)$, or low-dose (L; $n=6) \mathrm{PJ}$, vitamin $\mathrm{C}$ water (Vit $\mathrm{C} ; n=5)$; or sugar water $(\mathrm{CHO} ; n=13)$. High, mid and low dose PJ supplementation significantly decreased tissue loss versus plain water control $\left(* * p<0.0001,{ }^{*} p=0.01\right)$. There was no significant difference between the amount of tissue loss when comparing the plain water, vitamin $\mathrm{C}$, and $\mathrm{CHO}$ groups. 


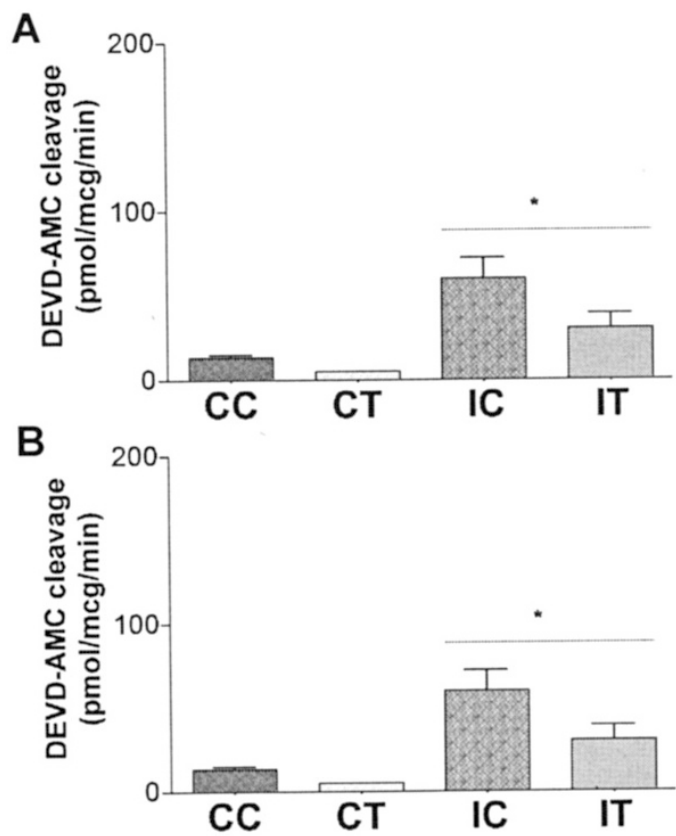

Figure 2. PJ decreases caspase-3 activity 24 hours after neonatal HI. DEVDAMC cleavage activity in ipsilateral plain water control $(n=13)$ versus high dose PJ $(n=15)$ exposed pups $(A)$ hippocampus $(* * p=0.0002)$ and $(B)$ cortex $(* p=0.0088)$ versus plain water control. DEVD-AMC assay was performed 24 hours after injury. Activity measured in the brain hemisphere contra-lateral to the side of injury are the same levels as in non-HI exposed animals. CC, contralateral control; CT, contralateral treated; IC, ipsilateral control; IT, ipsilateral treated.

group (Fig. 4). P7 pups from groups that received low- and middle-dose pomegranate juice had a small but significantly greater mean weight, and the sugar water control group had a significantly lower mean weight than the plain water control group. Weights at P14 were randomly assessed and showed similar variation. It is unlikely that the weight differences account for any of the effects of pomegranate juice, because the weights of the high-dose pomegranate juice group and plain water control group did not differ and there was no difference in extent of injury among any of the various control groups despite the small weight differences. All mouse pups from each litter were used in these experiments, although the sex of the pups was not recorded. As sex-dependent neuroprotection has been described in several rodent models $(41,42)$, future experiments will be required to sort out whether there are any sex-dependent differences in effects of pomegranate juice.

\section{DISCUSSION}

In this study, we demonstrated that supplementing the mouse maternal diet with pomegranate juice, a food highly enriched in polyphenols, in the peripartum period provides significant neuroprotection from hypoxic-ischemic injury to neonatal mice. The histologic protection is associated with a decrease in markers of apoptosis, specifically caspase-3 activity. Similar neuroprotective effects of foods with high polyphenol contents have been reported in an adult rodent models of stroke (16). To our knowledge, this is the first demonstration of neonatal neuroprotection accomplished through natural food supplementation of the maternal diet. The most significant neuroprotective effect was observed at the highest dose of pomegranate juice supplementation, equivalent to consumption of two 8-oz glasses of pomegranate juice per day in an adult human (30). At this dose, there was no statistically significant difference in pup weights between high-dose-treated and plain water control groups, suggesting that neither caloric intake nor body weight could account for the neuroprotective effect. This trial was conducted in C57BL6 mice; variation of therapeutic effect of treatments in different species has been described (43). Thus, further investigation of pomegranate juice's neuroprotective capabilities in other species is warranted. Histologic and biochemical analyses were performed at $24 \mathrm{~h}$ and $7 \mathrm{~d}$ after injury in this study. Although evolving cell death after HI has neared completion by several days after HI, further study of multiple time points after hypoxic-ischemic exposure would help to establish that pomegranate juice supplementation inhibits rather than delays evolution of brain injury.

The exact mechanisms underlying pomegranate juice's neuroprotective actions remain to be elucidated. Commercially available pomegranate juice is produced from pressing the whole fruit and heating the juice products; the resultant liquid thus contains a complex mixture of polyphenols $(20,44)$. These compounds undergo varying degrees of intestinal and hepatic metabolism, including O-methylation and glucuronidation with detection of $<10 \%$ of the parent compounds in urine and feces (45-49). Whereas intestinal absorption of polyphenols is well described, penetration into various target organs, specifically the placenta, is unknown $(50,51)$. In this study, we demonstrated the passage of ellagic acid from maternal serum to pup serum. Furthermore, at least one polyphenol-epigallocatechin gallate- has been shown to cross the murine blood-brain barrier in vivo; others have been demonstrated to cross an in vitro model of the blood-brain barrier $(52,53)$. The actual compound or compounds - or their synergistic combinationthat mediate this described neuroprotection are not yet clear. In our study, we looked for and detected the presence of one specific polyphenol, ellagic acid, in pup serum, thus establishing maternal-placental transfer of a pomegranate juice constituent. In vitro neuroprotection investigations of various polyphenols has found efficacy in the low micromolar range $(0.1-$ 10 ) with exposures of not more than $24 \mathrm{~h}(18,54)$. Although the concentration of ellagic acid in plasma was in the low nanomolar range, pomegranates contain numerous polyphenols $(25,26)$ (Aviram M, unpublished data, 2002). Thus, the total concentration of polyphenols in the plasma of the mouse pups is likely to have been significantly higher than that of only ellagic acid. It is conceivable that the total polyphenol concentration over the time period of exposure in our study potentially reached the low micromolar range in the serum that has been shown to exert antioxidant effects. In addition, because of the lipophilic nature of polyphenols, the concentrations achieved in the CNS with prolonged exposures may be significantly higher than in the serum. Studies to specifically measure brain polyphenol content will be required to fully address this issue.

One recognized polyphenol, resveratrol, inhibits LDL oxidation, modulates cyclooxygenase- 2 expression and activity, and possesses anti-inflammatory activity (55-57). Reactive 


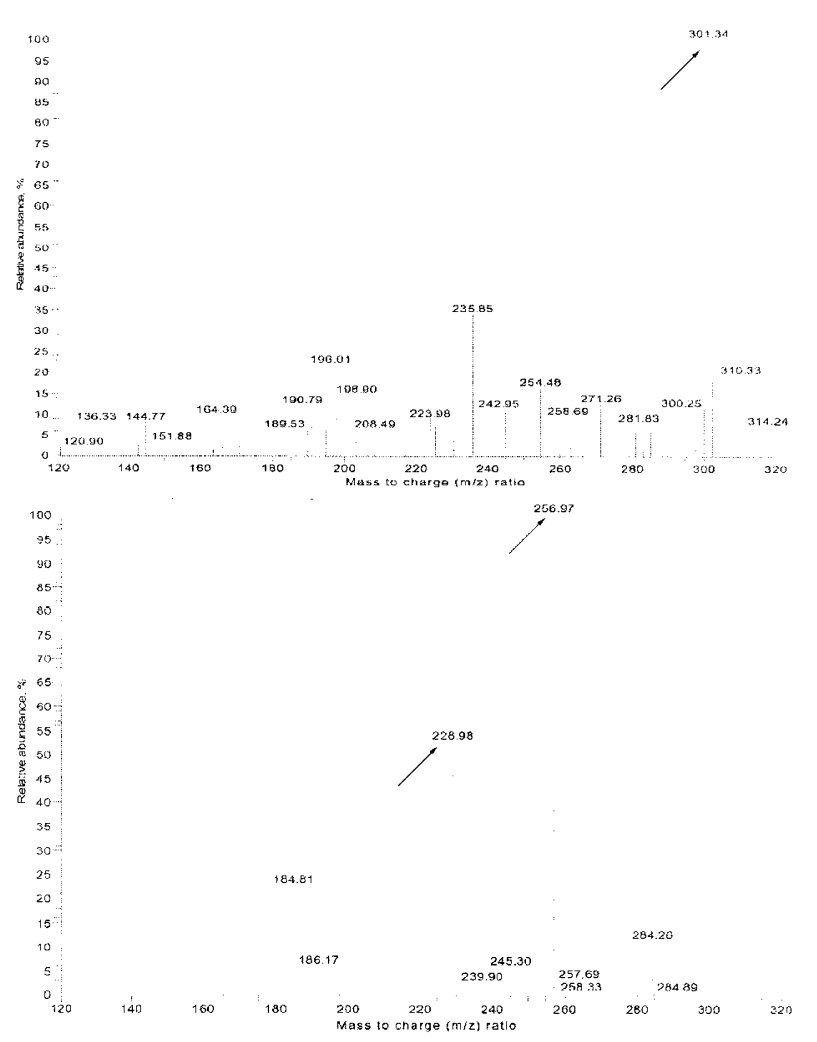

Figure 3. Ellagic acid in pup plasma. (A) Detection of ellagic acid at mass/charge ratio $-\mathrm{m} / \mathrm{z}\left(x\right.$ axis, $\left.\mathrm{M}-\mathrm{H}^{+}\right) 301$ (arrow) in plasma of P7 mouse pups suckling from dams that were fed pomegranate juice by LCMS. The relative abundance of the molecules along the $y$ axis is with a maximum of $100 \%$. (B) Presence of molecular ions at $\mathrm{m} / \mathrm{z} 257$ and 229 (arrows) via tandem LCMS distinguishes ellagic acid from quercetin.

nitrogen and oxygen species play important physiologic and pathologic roles in neonatal HI, and attenuation of synthesis of these compounds during $\mathrm{HI}$ has been shown to provide neuroprotection (58-60). In light of this, it is interesting to note that pomegranate juice has a significant antioxidant capacity $(51,61)$. Glutathione is a well-characterized reactive nitrogen and oxygen species scavenger in the brain, and catechins (another constituent of pomegranate juice) have been shown to increase intracellular glutathione levels and modulate glutathione peroxidase activity (62-65). Catechins also modulate tyrosine kinase and protein kinase $\mathrm{C}$ signal transduction pathways in vitro $(30,66-69)$. Although the roles of these signal pathways in HI-induced neurotoxicity are complex, protein kinase $\mathrm{C}$ has been demonstrated to play a role in microglial release of glutamate (70). Catechin and epicatechin have been shown to reduce ischemia and reperfusion injury in gerbils (71). Although these compounds (interestingly present in dark chocolate as well) possess potent antioxidant capacities, they also increase superoxide dismutase activity and have been shown to protect against brain lipid peroxidation $(61,72)$.

Inflammation and related interferons and interleukins have been clearly implicated in neonatal brain damage from HI (73-75). Pomegranate juice, in both in vitro and in vivo systems, has been shown to attenuate immune system activity as measured by macrophage LDL uptake and superoxide anion

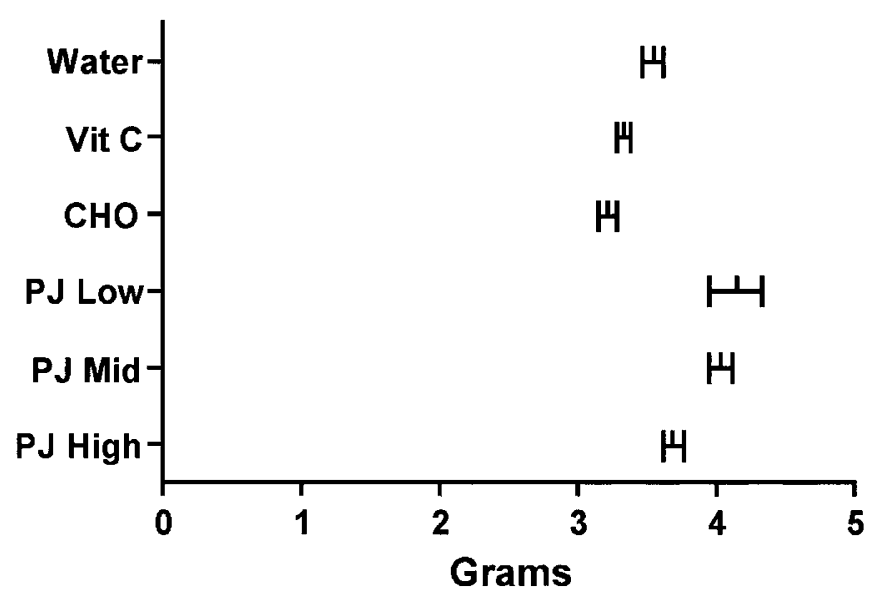

Figure 4. Pup weights measured at P7 immediately before left carotid ligation. There is no statistical difference in pup weights between the highdose-supplemented group and the water control group.

release $(29,30)$. These studies offer evidence that pomegranate juice may provide some degree of microglial and immune system quiescence during HI challenge.

Although no randomized, controlled trials to detect negative health effects of pomegranate juice consumption have been performed in pregnant women, there is no anecdotal evidence to suggest any harmful effects. Our study did not reveal any gross teratologic effects from maternal dietary pomegranate juice supplementation, although we did not survey specific pup organ histology. Specific investigation of long-term human fetal exposure to maternal dietary supplementation with pomegranate juice has not been performed; however, doses of 100 $\mu \mathrm{g}$ of pomegranate extract in a chick embryo model were nontoxic (76). Humans have consumed pomegranate juice since the beginning of recorded history without any reported adverse health consequences. In vivo studies of the most abundant polyphenol isolated from pomegranate juice-the ellagitannin punicalagin - found no histologic evidence of hepatotoxicity or renal toxicity or variation in liver aminotransferases or serum bilirubin in adult rats that were fed a diet enhanced with punicalagin for $37 \mathrm{~d}$ (77). It will be important in further studies in humans to determine whether there are any short- or long-term risks of pomegranate juice to pregnant women and the developing fetus as these issues have not been examined in this study.

In this study, the maternal diet was supplemented with pomegranate juice beginning at the last third of gestation and ending after the pups were killed (either at $24 \mathrm{~h}$ or $7 \mathrm{~d}$ after hypoxic-ischemic exposure). Therefore, we cannot determine whether the neuroprotective agent or agents were provided during gestation, postnatal life, or both. In future studies, it will be interesting to determine whether specific polyphenols or other compounds in pomegranate juice are individually neuroprotective and, if so, by what mechanisms they exert their effects.

\section{CONCLUSIONS}

Evidence is gathering that suggests that pomegranate juice may modify the natural history of an expanding repertoire of 
diseases. Specifically, pomegranate juice is being investigated as an adjuvant in treatment of atherogenesis, breast cancer, and prostate cancer $(28,78)$. On the basis of our study, we conclude that maternal dietary supplementation with pomegranate juice, a food rich in polyphenols, is neuroprotective to the neonatal mouse brain. This suggests that further studies with pomegranate juice in other species, including humans, are warranted. Study of specific, purified, polyphenol compounds or their metabolites and mixtures of polyphenols present in pomegranate juice will help to further elucidate neuroprotective mechanisms.

Acknowledgments. We are grateful for the technical assistance provided by Maia Parsadianian, Tim West, and Rupo Lee.

\section{REFERENCES}

1. Hankins GD, Speer M 2003 Defining the pathogenesis and pathophysiology of neonatal encephalopathy and cerebral palsy. Obstet Gynecol 102:628-636

2. Shevell MI 2004 The "Bermuda triangle" of neonatal neurology: cerebral palsy, neonatal encephalopathy, and intrapartum asphyxia. Semin Pediatr Neurol 11:24-30

3. Volpe JJ 2001 Neurology of the Newborn. WB Saunders Co, Philadelphia, 314-369

4. Back SA 2001 Recent advances in human perinatal white matter injury. Prog Brain Res 132:131-147

5. Ferriero DM, Holtzman DM, Black SM, Sheldon RA 1996 Neonatal mice lacking neuronal nitric oxide synthase are less vulnerable to hypoxic-ischemic injury. Neurobiol Dis 3:64-71

6. Johnston MV, Trescher WH, Ishida A, Nakajima W 2000 Novel treatments after experimental brain injury. Semin Neonatol 5:75-86

7. McDonald JW, Johnston MV 1990 Physiological and pathophysiological roles of excitatory amino acids during central nervous system development. Brain Res Brain Res Rev 15:41-70

8. Thordstein M, Bagenholm R, Thiringer K, Kjellmer I 1993 Scavengers of free oxygen radicals in combination with magnesium ameliorate perinatal hypoxic-ischemic brain damage in the rat. Pediatr Res 34:23-26

9. Ishida A, Trescher WH, Lange MS, Johnston MV 2001 Prolonged suppression of brain nitric oxide synthase activity by 7-nitroindazole protects against cerebral hypoxic-ischemic injury in neonatal rat. Brain Dev 23:349-354

10. Cheng Y, Deshmukh M, D'Costa A, Demaro JA, Gidday JM, Shah A, Sun Y, Jacquin MF, Johnson EM, Holtzman DM 1998 Caspase inhibitor affords neuroprotection with delayed administration in a rat model of neonatal hypoxic-ischemic brain injury. J Clin Invest 101:1992-1999

11. Cheng Y, Gidday JM, Yan Q, Shah AR, Holtzman DM 1997 Marked age-dependent neuroprotection by brain-derived neurotrophic factor against neonatal hypoxicischemic brain injury. Ann Neurol 41:521-529

12. Northington FJ, Ferriero DM, Graham EM, Traystman RJ, Martin LJ 2001 Early neurodegeneration after hypoxia-ischemia in neonatal rat is necrosis while delayed neuronal death is apoptosis. Neurobiol Dis 8:207-219

13. Nakajima W, Ishida A, Lange MS, Gabrielson KL, Wilson MA, Martin LJ, Blue ME, Johnston MV 2000 Apoptosis has a prolonged role in the neurodegeneration after hypoxic ischemia in the newborn rat. J Neurosci 20:7994-8004

14. CDC 2004 Spina bifida and anencephaly before and after folic acid mandate-United States, 1995-1996 and 1999-2000. MMWR Morb Mortal Wkly Rep 53:362-365

15. Etus V, Altug T, Belce A, Ceylan S 2003 Green tea polyphenol (-)-epigallocatechin gallate prevents oxidative damage on periventricular white matter of infantile rats with hydrocephalus. Tohoku J Exp Med 200:203-209

16. Sweeney MI, Kalt W, MacKinnon SL, Ashby J, Gottschall-Pass KT 2002 Feeding rats diets enriched in lowbush blueberries for six weeks decreases ischemia-induced brain damage. Nutr Neurosci 5:427-431

17. Ortiz D, Shea TB 2004 Apple juice prevents oxidative stress induced by amyloid-beta in culture. J Alzheimers Dis 6:27-30

18. Levites Y, Amit T, Mandel S, Youdim MB 2003 Neuroprotection and neurorescue against Abeta toxicity and PKC-dependent release of nonamyloidogenic soluble precursor protein by green tea polyphenol (-)-epigallocatechin-3-gallate. FASEB J 17:952-954

19. Dajas F, Rivera F, Blasina F, Arredondo F, Echeverry C, Lafon L, Morquio A, Heizen H 2003 Cell culture protection and in vivo neuroprotective capacity of flavonoids. Neurotox Res 5:425-432

20. Ben Nasr C, Ayed N, Metche M 1996 Quantitative determination of the polyphenolic content of pomegranate peel. Z Lebensm Unters Forsch 203:374-378

21. Kostrzewa RM, Segura-Aguilar J 2003 Novel mechanisms and approaches in the study of neurodegeneration and neuroprotection. A review. Neurotox Res 5:375-383

22. Latruffe N, Delmas D, Jannin B, Malki MC, Passilly-Degrace P, Berlot JP 2002 Molecular analysis on the chemopreventive properties of resveratrol, a plant polyphenol microcomponent. Int J Mol Med 10:755-760

23. Howitz KT, Bitterman KJ, Cohen HY, Lamming DW, Lavu S, Wood JG, Zipkin RE, Chung P, Kisielewski A, Zhang LL, Scherer B, Sinclair DA 2003 Small molecule activators of sirtuins extend saccharomyces cerevisiae lifespan. Nature 425:191-196
24. Hall SS 2003 Longevity research. In vino vitalis? Compounds activate life-extending genes. Science 301:1165

25. Aviram M 2002 Pomegranate juice as a major source for polyphenolic flavonoids and its most potent antioxidant against LDL oxidation and atherosclerosis. Free Radic Res 36(Suppl 1): 71-72

26. Gil MI, Tomas-Barberan FA, Hess-Pierce B, Holcroft DM, Kader AA 2000 Antioxidant activity of pomegranate juice and its relationship with phenolic composition and processing. J Agric Food Chem 48:4581-4589

27. Anesini C, Perez C 1993 Screening of plants used in argentine folk medicine for antimicrobial activity. J Ethnopharmacol 39:119-128

28. Kim ND, Mehta R, Yu W, Neeman I, Livney T, Amichay A, Poirier D, Nicholls P, Kirby A, Jiang W, Mansel R, Ramachandran C, Rabi T, Kaplan B, Lansky E 2002 Chemopreventive and adjuvant therapeutic potential of pomegranate (punica granatum) for human breast cancer. Breast Cancer Res Treat 71:203-217

29. Kaplan M, Hayek T, Raz A, Coleman R, Dornfeld L, Vaya J, Aviram M 2001 Pomegranate juice supplementation to atherosclerotic mice reduces macrophage lipid peroxidation, cellular cholesterol accumulation and development of atherosclerosis. J Nutr 131:2082-2089

30. Aviram M, Dornfeld L, Rosenblat M, Volkova N, Kaplan M, Coleman R, Hayek T, Presser D, Fuhrman B 2000 Pomegranate juice consumption reduces oxidative stress, atherogenic modifications to LDL, and platelet aggregation: studies in humans and in atherosclerotic apolipoprotein E-deficient mice. Am J Clin Nutr 71:1062-1076

31. Aviram M, Dornfeld L 2001 Pomegranate juice consumption inhibits serum angiotensin converting enzyme activity and reduces systolic blood pressure. Atherosclerosis 158:195-198

32. Vannucci RC, Vannucci SJ 1997 A model of perinatal hypoxic-ischemic brain damage. Ann NY Acad Sci 835:234-249

33. Han BH, DeMattos RB, Dugan LL, Kim-Han JS, Brendza RP, Fryer JD, Kierson M, Cirrito J, Quick K, Harmony JA, Aronow BJ, Holtzman DM 2001 Clusterin contributes to caspase-3-independent brain injury following neonatal hypoxia-ischemia. Nat Med 7:338-343

34. Gibson ME, Han BH, Choi J, Knudson CM, Korsmeyer SJ, Parsadanian M, Holtzman DM 2001 BAX contributes to apoptotic-like death following neonatal hypoxiaischemia: evidence for distinct apoptosis pathways. Mol Med 7:644-655

35. Rice JE, Vannucci RC, Brierley JB 1981 The influence of immaturity on hypoxicischemic brain damage in the rat. Ann Neurol 9:131-141

36. Han BH, Holtzman DM 2000 BDNF protects the neonatal brain from hypoxicischemic injury in vivo via the ERK pathway. J Neurosci 20:5775-5781

37. Seeram NP, Lee R, Hardy ML, Heber D 2005 Rapid large scale purification of ellagitannins from pomegranate husk, a by-product of the commercial juice industry. Sep Purific Tech 41:49-55

38. Seeram NP, Lee R, Heber D 2004 Bioavailability of ellagic acid in human plasma after consumption of ellagitannins from pomegranate (Punica granatum L.) juice. Clin Chim Acta 348:63-68

39. Han BH, D'Costa A, Back SA, Parsadanian M, Patel S, Shah AR, Gidday JM, Srinivasan A, Deshmukh M, Holtzman DM 2000 BDNF blocks caspase-3 activation in neonatal hypoxia-ischemia. Neurobiol Dis 7:38-53

40. Mullen W, Yokoto T, Lean ME, Crozier A 2003 Analysis of ellagitanins and conjugates of ellagic acid and quercetin in raspberry fruits by $\mathrm{lC}-\mathrm{MSn}$. Phytochemistry 64:617-624

41. Hagberg H, Wilson MA, Matsushita H, Zhu C, Lange M, Gustavsson M, Poitras MF, Dawson TM, Dawson VL, Northington F, Johnston MV 2004 PARP-1 gene disruption in mice preferentially protects males from perinatal brain injury. $\mathrm{J}$ Neurochem 90:1068-1075

42. Bona E, Hagberg H, Loberg EM, Bagenholm R, Thoresen M 1998 Protective effects of moderate hypothermia after neonatal hypoxia-ischemia: Short- and long-term outcome. Pediatr Res 43:738-745

43. Tsuji M, Wilson MA, Lange MS, Johnston MV 2004 Minocycline worsens hypoxicischemic brain injury in a neonatal mouse model. Exp Neurol 189:58-65

44. Artik N 1998 Determination of phenolic compounds in pomegranate juice by using HPLC. Fruit Process 492-499

45. Cerda B, Llorach R, Ceron JJ, Espin JC, Tomas-Barberan FA 2003 Evaluation of the bioavailability and metabolism in the rat of punicalagin, an antioxidant polyphenol from pomegranate juice. Eur J Nutr 42:18-28

46. Lei F, Xing DM, Xiang L, Zhao YN, Wang W, Zhang LJ, Du LJ 2003 Pharmacokinetic study of ellagic acid in rat after oral administration of pomegranate leaf extract. J Chromatogr B Analyt Technol Biomed Life Sci 796:189-194

47. Okushio K, Suzuki M, Matsumoto N, Nanjo F, Hara Y 1999 Identification of (-)-epicatechin metabolites and their metabolic fate in the rat. Drug Metab Dispos 27:309-316

48. Rice-Evans C, Spencer JP, Schroeter H, Rechner AR 2000 Bioavailability of flavonoids and potential bioactive forms in vivo. Drug Metabol Drug Interact 17:291-310

49. Glasser G, Graefe EU, Struck F, Veit M, Gebhardt R 2002 Comparison of antioxidative capacities and inhibitory effects on cholesterol biosynthesis of quercetin and potential metabolites. Phytomedicine 9:33-40

50. Spencer JP, Schroeter H, Rechner AR, Rice-Evans C 2001 Bioavailability of flavan3-ols and procyanidins: gastrointestinal tract influences and their relevance to bioactive forms in vivo. Antioxid Redox Signal 3:1023-1039

51. Serafini M, Bugianesi R, Maiani G, Valtuena S, De Santis S, Crozier A 2003 Plasma antioxidants from chocolate. Nature 424:1013

52. Suganuma M, Okabe S, Oniyama M, Tada Y, Ito H, Fujiki H 1998 Wide distribution of [3h](-)-epigallocatechin gallate, a cancer preventive tea polyphenol, in mouse tissue. Carcinogenesis 19:1771-1776

53. Youdim KA, Dobbie MS, Kuhnle G, Proteggente AR, Abbott NJ, Rice-Evans C 2003 Interaction between flavonoids and the blood-brain barrier: in vitro studies. J Neurochem 85:180-192 
54. Spencer JP, Rice-Evans C, Williams RJ 2003 Modulation of pro-survival Akt/protein kinase B and ERK1/2 signaling cascades by quercetin and its in vivo metabolites underlie their action on neuronal viability. J Biol Chem 278:34783-34793

55. Zhuang H, Kim YS, Koehler RC, Dore S 2003 Potential mechanism by which resveratrol, a red wine constituent, protects neurons. Ann NY Acad Sci 993:276-286; discussion 287-288

56. Subbaramaiah K, Chung WJ, Michaluart P, Telang N, Tanabe T, Inoue H, Jang M, Pezzuto JM, Dannenberg AJ 1998 Resveratrol inhibits cyclooxygenase-2 transcription and activity in phorbol ester-treated human mammary epithelial cells. J Biol Chem 273:21875-21882

57. Manna SK, Mukhopadhyay A, Aggarwal BB 2000 Resveratrol suppresses tnfinduced activation of nuclear transcription factors NF-kappa B, activator protein-1, and apoptosis: potential role of reactive oxygen intermediates and lipid peroxidation. J Immunol 164:6509-6519

58. Peeters-Scholte C, Koster J, Veldhuis W, van den Tweel E, Zhu C, Kops N, Blomgren K, Bar D, van Buul-Offers S, Hagberg H, Nicolay K, van Bel F, Groenendaal F 2002 Neuroprotection by selective nitric oxide synthase inhibition at 24 hours after perinatal hypoxia-ischemia. Stroke 33:2304-2310

59. Coyle JT, Puttfarcken P 1993 Oxidative stress, glutamate, and neurodegenerative disorders. Science 262:689-695

60. Hamrick SE, Ferriero DM 2003 The injury response in the term newborn brain: can we neuroprotect? Curr Opin Neurol 16:147-154

61. Youdim KA, Spencer JP, Schroeter H, Rice-Evans C 2002 Dietary flavonoids as potential neuroprotectants. Biol Chem 383:503-519

62. Savaskan E, Olivieri G, Meier F, Seifritz E, Wirz-Justice A, Muller-Spahn F 2003 Red wine ingredient resveratrol protects from beta-amyloid neurotoxicity. Gerontology 49:380-383

63. Varghese CD, Nair SC, Panikkar B, Panikkar KR 1993 Effect of asoka on the intracellular glutathione levels and skin tumour promotion in mice. Cancer Lett 69:45-50

64. Chopra K, Singh D, Chander V 2004 Nephrotoxicity and its prevention by catechin in ferric nitrilotriacetate promoted oxidative stress in rats. Hum Exp Toxicol 23:137143

65. Jeon SE, Choi-Kwon S, Park KA, Lee HJ, Park MS, Lee JH, Kwon SB, Park KC 2003 Dietary supplementation of (+)-catechin protects against UVB-induced skin damage by modulating antioxidant enzyme activities. Photodermatol Photoimmunol Photomed 19:235-241
66. Han YS, Zheng WH, Bastianetto S, Chabot JG, Quirion R 2004 Neuroprotective effects of resveratrol against beta-amyloid-induced neurotoxicity in rat hippocampal neurons: involvement of protein kinase C. Br J Pharmacol 141:997-1005

67. Conte A, Pellegrini S, Tagliazucchi D 2003 Effect of resveratrol and catechin on pc12 tyrosine kinase activities and their synergistic protection from beta-amyloid toxicity. Drugs Exp Clin Res 29:243-255

68. de Pascual-Teresa S, Johnston KL, DuPont MS, O'Leary KA, Needs PW, Morgan LM, Clifford MN, Bao Y, Williamson G 2004 Quercetin metabolites downregulate cyclooxygenase-2 transcription in human lymphocytes ex vivo but not in vivo. J Nutr 134:552-557

69. Plumb GW, de Pascual-Teresa S, Santos-Buelga C, Rivas-Gonzalo JC, Williamson G 2002 Antioxidant properties of gallocatechin and prodelphinidins from pomegranate peel. Redox Rep 7:41-46

70. Nakamura Y, Ohmaki M, Murakami K, Yoneda Y 2003 Involvement of protein kinase $\mathrm{C}$ in glutamate release from cultured microglia. Brain Res 962:122-128

71. Inanami O, Watanabe Y, Syuto B, Nakano M, Tsuji M, Kuwabara M 1998 Oral administration of (-)catechin protects against ischemia-reperfusion-induced neuronal death in the gerbil. Free Radic Res 29:359-365

72. Sun GY, Xia J, Draczynska-Lusiak B, Simonyi A, Sun AY 1999 Grape polyphenols protect neurodegenerative changes induced by chronic ethanol administration. Neuroreport 10:93-96

73. Kadhim H, Tabarki B, Verellen G, De Prez C, Rona AM, Sebire G 2001 Inflammatory cytokines in the pathogenesis of periventricular leukomalacia. Neurology 56:1278-1284

74. Yoon BH, Romero R, Park JS, Kim CJ, Kim SH, Choi JH, Han TR 2000 Fetal exposure to an intra-amniotic inflammation and the development of cerebral palsy at the age of three years. Am J Obstet Gynecol 182:675-681

75. Grether JK, Nelson KB, Dambrosia JM, Phillips TM 1999 Interferons and cerebral palsy. J Pediatr 134:324-332

76. Vidal A, Fallarero A, Pena BR, Medina ME, Gra B, Rivera F, Gutierrez Y, Vuorela PM 2003 Studies on the toxicity of Punica granatum L. (Punicaceae) whole fruit extracts. J Ethnopharmacol 89:295-300

77. Cerda B, Ceron JJ, Tomas-Barberan FA, Espin JC 2003 Repeated oral administration of high doses of the pomegranate ellagitannin punicalagin to rats for 37 days is not toxic. J Agric Food Chem 51:3493-3501

78. Longtin R 2003 The pomegranate: nature's power fruit? J Natl Cancer Inst 95:346348 